\title{
Against the Ugliness of Age: \\ Towards an Erotics of the Aging Sexual Body
}

\author{
Allison Moore \\ Edge Hill University, Ormskirk \\ Paul Reynolds
}

Edge Hill University, Ormskirk

\begin{abstract}
Within the heteronormative construction, older people are positioned as asexual, post-sexual or predatory on young bodies. Ageist assumptions deny their sexual desires exist at all or, if they are acknowledged, frame them within pathological medical, sexological and cultural discourses that characterize older sexual agency as grotesque, ugly, unattractive and sexually undesirable. These normative constructions have a negative impact on older sexual subjectivities. This article begins to develop a constructive representational form - or erotics - of aging sex and sexuality. Queer, as a deconstructionist, anti-foundational and anti-essential perspective, would seem the most prominent means by which to challenge pathologies of the ageing body and ageing sexuality. However, this discussion will suggest that there is both scope and limitations with regards to the ability of Queer critiques to undermine ageist erotophobia. Whilst queer proposes that we are free to construct and reconstruct our sexuality in multiple ways, our changing subjectivities are not just experienced emotionally and intra-psychically but are also bounded by our physicality. Our ageing corporeality prevents a constant and continuous reinvention of the sexual self. This does not preclude an erotics of age that -moves away from genito-centric and heteronormative/ homonormative constructions of sexuality and open up the potential for an erotic aged sex and sexual intimacy.
\end{abstract}

Key words: heteronormative, pathology, age, sex, desire, erotics

... The body is a materialization, a socially mediated formation, lived individually and in communities as real effects. The physicality of the body establishes some of the potentials and limits for what we can do with our bodies, but these limits are not always absolutely fixed. The social world enters the physical body as we develop skills and capacities, altering even the body's molecular structure, its anatomy, physiology and metabolism. The body is thus a sturdy but fragile thing, an historical matter of political struggle. - Jacquelyn N. Zita, Body Talk, p. 4

Body is certitude shattered and blown to bits. Nothing's more proper, nothing's more foreign to our old world - Jean-Luc Nancy, Corpus, p. 5 


\section{Introduction}

Jean-Luc Nancy's corrective to discursive articulations of the body is that they often dissolve the body into discourse, approaching it from our mind's eye rather than in the flesh, materially, as corpus. Our relationship with the corpus is an act of confronting the foreign, the obverse, the other. As he observes:

The body proper, the foreign body; hoc est enim displays the body proper, makes it present to the touch, serves it up as a meal. . . But instantly, always, the body on display is foreign, a monster that can't be swallowed...

And all thoughts of the "body-proper," laborious efforts at reappropriating what we used to consider, impatiently, as "objectified" or "reified," all such thoughts about the body are comparably contorted; in the end, they only expel the thing we desired. (Nancy 5)

In Nancy's narrative, this indigestible body is a symptom of western enlightenment reason, where the idea, or ideal, of the body has replaced flesh. The desire to possess and consume the body 'exscribes' or translates it into a digestible form which we take to be the body, whereas looking at bodies - corpus - as they are confronts the indigestible, beyond discourse, present in the material yet in our examination foreign to us (Nancy 3-9).

This problem of the intelligibility of the body - an enduring and always agonistic, insoluble struggle - leaves how we construct our bodies, positively or otherwise, within the domain of discourse and discursive practices, where pedagogisation imposes upon attempts to 'come to terms' with the bodies we inhabit and the bodies we touch (Foucault 1976, 1984a, 1984b). Whilst the problem of the intelligibility of the body might be an enduring constant in struggles to possess the self and bring it under some juxtaposition with the consciousness that provides for desire, pleasure and peace, it is the problem of discursive struggles against pernicious and disabling discourses that characterises the everyday sense of struggle against pathology and prejudice.

A key domain in the struggle is the articulation of the sexed body. The sexed body, translated into consumable discourse, is young, fit, supple, lithe, toned and shaped to compose desire in the mind's eye, whatever the object or subject of desire may be. Sexuality, plastic in identity in 
contemporary societies, is normatively youthful. Diverse representations of desire, whether heterosexual or not, vanilla or 'kinky', have a broad conformity to masculine and feminine 'Vitruvian's', proportionally pleasing with the completeness of strong against yielding, control against abandon, breach against violation. ${ }^{46}$ What does not meet that normative cast is the nonsexual or the fetishised, the exception that amuses or repels. The struggle for the sexual gaze, then, is to both come to terms with the corpus, insofar as it can be made intelligible in a discursive world where its representation is fetishised in media and culture, and at the very least to engage with or produce constructive discourses of the body to avoid exceptionality where it debilitates. Yet, and as if proof for Nancy's claims about the indigestibility of our bodies, we include in that exception a condition that none escape the condition of aging and being 'old' except those who die you and are remembered in frozen youth.

Within but not exclusive to the heteronormative construction of sex and sexuality, older people are positioned as asexual, post-sexual or undesirable, and where they enter the sexual world it is to be predatory on young bodies that represent their loss and their desire. The aged body is naturalised, denied desire, or where there is acknowledgement that sexual desire is still present, medical, sexological and cultural discourses are constructed with pathological representations. Aging bodies are subject to sexual dysfunction, frailty, fragility and impaired performance, or fetishized notions of sexual relations, such as 'old with young'. Aging bodies are seen in a range of positions from being incapable of physically engaging in sexual activity, to being sexualised in only fetishised form, to being characterised as grotesque, ugly, unattractive and sexually undesirable. Only where the body can be remade young in its appearance, whether by cosmetic surgery or other somatechnics, is there even the semblance of extending the 'shelf life' of desirability.

If we follow Nancy and all encounters with the body challenge the subjectivity we constitute, these normative constructions about older people's sexuality, with their different forms of sensual lack, have significant negative impacts on their sexual subjectivities. They constitute a pedagogy that strips away whatever fleeting senses of sensual desire and interaction formed in their 'prime' as part of the process by which corporeality is conceived as withering and dying. The erotophobia that

\footnotetext{
46 'Vitruvian' is used as metaphor, here, and one Nancy would appreciate. Da Vinci's model of human proportions is a representation of perfection that, in its shaping has bow legs and for one critic, asymptomatic left inguinal hernia. See: http://www.dailymail.co.uk/sciencetech/article-2562403/How-bulgegroin-revealed-Da-Vincis-Vitruvian-Man-wasnt-perfect-specimen-all.html accessed 20/05/2015
} 
arises from these normative articulations of age wear down the sexual subject and reduce them to the characteristics of being 'aged'. They are beyond and outside of being sexual.

Zita's observation provides a starting point for exploring both the construction of aging sexuality and the possibilities by which pathological pedagogies can be subverted and an 'erotics' of the aging sexual subject can be explored. The task is to develop a constructive representational form or erotics - of aging sex and sexuality by which older people can re-enter the discursive world of being sexual. This form involves not just the replacement of negative with positive, but a recognition that for older people, coming to terms with the corpus has its own material challenges. This is not to argue that an erotics of the ageing body provides special insight to see the corpus beyond discursive contexts, but only that in constructing an erotics of the ageing body - and note that they are represented as real bodies, aging rather than in a particular stasis called 'old' - the juxtaposition between corpus and discourse is more acute. This latter is important, since the body is both a constant in our gaze but always aging in its corporeality. The gaze is discursively articulated as 'old' in relation to 'young', and thereby always discursively ordered negatively, whereas aging is a constant for all bodies, requiring different strategies or changing re-articulations of the desirable to accommodate.

If pathological, prejudicial and debilitating discourses of constructions of body, sexuality and desire are to be subverted and dismantled, it is necessary to look elsewhere from conventional naturalised, biological and normalised foundations. Queer, as a deconstructionist, anti-foundational and anti-essential perspective, would seem a potent means by which to challenge pathologies of the aged body and ageing sexuality. However, there is both scope and limitations with regards to the ability of Queer critiques to undermine ageist erotophobia. Queer proposes that we are free to construct and reconstruct our sexuality in multiple ways, and that our bodies should be understood as a text upon which we can inscribe and re-inscribe multiple and multi-layered meanings that reflect our changing subjectivities. This certainly offers the opportunity for sexual agency in any context, including that of aging. Yet, our changing subjectivities are not just experienced emotionally and intra-psychically but are also bounded by our physicality. As such, our corporeality and especially an ageing corporeality, limits and may prevent a constant and continuous reinvention of the sexual self. At the same time, an ageing body due to physical and, to a lesser extent, cognitive changes, might require individuals to move away from genito-centric and 
heteronormative/homonormative constructions of sexuality and open up the potential for queering sex and sexual intimacy.

In this discussion, we assess the problems and possibilities of a queer critique of the aged 'ugly' body and sexual desirability, and explore the intersection of discursive and materialist critiques to provide a less provisional and more applicable basis for an erotics of aging sex and sexuality.

\section{Sex, Intimacy and Ageing}

Sex and sexuality have taken centre stage in contemporary Western societies and are considered essential features of what Giddens (1991) called the reflexive project of self, a fluid and dynamic process whereby individuals are no longer restrained by structural barriers but instead are free to exercise choice and reflexivity in the creation and recreation of their identities. These choice narratives are thought to have led to the emergence and celebration of a myriad of possibilities of intimate expression. However, whilst there has undoubtedly been a proliferation of representations of sex and sexuality in the Anglophone West, to such an extent that some commentators have argued that we now live in a sex-saturated or hypersexual world, the meanings ascribed to these representations have become restricted rather than more plural. Sex continues to be the preserve of young able-bodied adults and continues to be normatively constructed as heterosexual. Within this context, it is assumed that those individuals who fall outside the narrow parameters of young adulthood are not, or should not be, sexual. Children and young people under the age of majority are positioned as asexual or pre-sexual and sexuality is seen to be something that they must be protected from. Older people are positioned as asexual or post-sexual and sexuality is seen as irrelevant to them. Until relatively recently, older people were viewed "as not sexually desirable, not sexually desirous and not sexually capable" (Vares 503). Indeed, so pervasive is this ageist erotophobia that "many older people see themselves as too old for sex" (Bouman et al. 153).

Despite the fact that many Western societies have witnessed the growth in ageing populations over the last two decades and there has been a growing awareness that sexual desire and sexual response does not suddenly disappear in old age, myths and stereotypes about older people's sexuality persist. According to Oppenheimer (2002), it is possible to identify four distinct but related attitudes regarding sexuality, intimacy and older people. 
The first is "the attitude of discreet silence; it's nicer not to talk of such things" (Oppenheimer 872) Although there might be a positive aspect to this in so far as older people's privacy is maintained because others do not want to intervene, do not want to ask questions because they do not want to know/hear the answers, there are also clearly negative connotations because older people's sexuality is silenced. Ken Plummer $(1995,2001,2003)$ has identified telling sexual stories, making public what was hitherto private, as an essential component of intimate citizenship. The attitude of discreet silence is the elder equivalent of 'Don't Ask, Don't Tell', the United Sates policy on gay personnel in the military which was enforced for many years.

The second attitude is the attitude of disgust. "Sex in old people is considered ugly ... grotesque and incongruous. . . . This attitude has a long cultural tradition; images of lecherous old men purchasing unwilling maidens, or of pained madams tempting youths to their downfall" (Oppenheimer 873) The notions of disgust and grotesque used here are underpinned by two taboos. The first concerns the incest taboo (Oppenheimer, 2002) or Western cultural prohibitions against intergenerational intimacy where older people, usually men, are portrayed as predatory on the supposed innocence and naivety of youth. Normative assumptions about youth sexuality and the sexuality of older people are, therefore, maintained and perpetuated. The second sense of the grotesque implied in this attitude concerns the ageing body itself as ugly and incongruous with sexual desire and desirability. In her discussion of the scarcity of media representations of sexuality in later life, Tina Vares (2009) suggests that this is due, largely, to the construction of elder sexuality as 'unwatchable', ugly and grotesque. However, this, too, is a gendered concept of the grotesque as it is women's ageing bodies that generate the greatest levels of disgust (Sontag, 1997; Oberg, 2003; Vares, 2009). Where the attitude of discreet silence renders elder sexuality as unspeakable, the attitude of disgust positions it as unimaginable or unthinkable.

The third attitude towards ageing sexuality is characterised by Oppenheimer as 'upbeat'. This can be seen as an attempt to challenge negative stereotypes of sexuality in later life and raise awareness about the continuing importance of sexual desire and intimacy as one ages. To illustrate this attitude, Oppenheimer cites an example of a car sticker that states "I'm not a dirty old man, I'm a sexy senior citizen" (873). However, replacing negative stereotypes with positive stereotypes still relies on homogenising assumptions and is still dehumanising (Thompson, 1998, 2001; UdisKessler, 1996). Not only does the 'upbeat' attitude create new normative standards of ageing 
sexuality, it can also deny the lived experiences of the many older people who do experience problems with regards to their sexual functioning.

The final attitude is, what Oppenheimer calls, "'tunnel vision': the mental set that conceives of sexuality only in terms of genital organs and of relationships as only heterosexual" (873). This attitude ignores the vast array of fantasies, desires and actions that sexuality encompasses. Further, not only does the dominance of heteronormativity deny the sexuality of lesbian, gay and bisexual elders, because of the continued assumptions about the ageing body as frail and in decline, there is a belief that older heterosexual men and women are unable to engage in penile-vaginal penetration and, therefore, elder sexuality is seen as impossible.

Existing alongside these largely negative attitudes towards ageing and sexuality, and somewhat contradictorily, is the view that lifelong sexual functioning is identified as one of the key components of 'positive ageing', 'successful ageing' or ageing well (Gott, 2006; Sandberg, 2008). For men, this means the ability to achieve and maintain an erection. Marshall and Katz (59) note: "The erect penis is now elevated to the status of a vital organ" but it is not just the presence of the erect penis that acts as an indicator of sexual functioning in older men, it is also its ability to penetrate (Sandberg, 2008). Successful sexual functioning for women, however, seems to be limited to the ability to be penetrated. Ageing well with regards to sexuality then reinforces heteronormativity and perpetuates, what Tamsin Wilton has called genital identities, which are predicated on the assumption that "a body with a vagina and uterus is allocated meanings that include its being for penetration / impregnation by a penis, while the meanings of a body which has a penis include its being for penetrating / impregnating a vagina / uterus" (104).

Such is the centrality attached to sexual function in narratives of 'successful ageing' that an inability to be sexually functional has been characterised by some public health and government officials as a public health concern and potential epidemic, particularly with respect to older men experiencing erectile dysfunction (see Gott 2006 and Mashall \& Katz, 2002 for a more detailed discussion of this development). The framing of sexuality in later life as in 'natural' decline positions it as inherently dysfunctional, which, in turn, legitimates medical and pharmacological intervention in the form of medications like Viagra, for example, in order to prevent a public health crisis. In other words, successful ageing assumes successful sexual functioning and requires older people to conform to a 
neoliberal model of individualism, management of risk and bodily regulation. It is the individual's responsibility to ensure that they access the necessary treatments and adhere to the required bodily regimes in order to remain "forever functional" (Marshall and Katz 59).

This example gives a powerful caution to any critical engagement with the erotophobia of the aging sexual body. There is a distinction between eroticising the aging sexual body and augmenting or procedurally intervening with the body to preserve characteristics - like maximal function - that are the domain of youth. It is a fine distinction, and cosmetic strategies for treating the ageing sexual body might straddle both sides. It is not, however, in itself a response to erotophobia to engage in strategies that are focused on 'turning back the clock' and thus preserving the basis of erotophobic pathology.

\section{Re-constructing the sexual aging body: Queer?}

The starting point for re-constructing the aged body as sexual would appear to be with a conception of sexuality that recognises fluidity and plasticity rather than rigidity in how sexuality and the sexual body are seen. The most prominent approach to take this position is queer. Although usually associated with lesbian, gay, bisexual and trans theorising, politics and activism, which seek to deconstruct pathological discourses of identity and behaviour, queer approaches have a broader purview. By its very nature, queer can be difficult to categorise and resists easy definition because of the diversity and divergence of opinion that falls under the 'queer umbrella'. David Halperin states, "Queer is by definition whatever is at odds with the normal, the legitimate, the dominant. There is nothing in particular to which it necessarily refers." In other words, queer is always and necessarily relational; "a positionality vis-à-vis the normative" (Halperin 62). It is precisely its relationship to the normative that makes queer theory so appealing in theorising ageing sexuality. Normative sexuality is not only heterosexual but also age-defined, inaccessible to or illegitimate for those considered too old (or too young). Its relationality, and by extension, its challenge to the normative, means that queer "can be taken up by anyone who feels marginalised as a result of their sexual practices" (Halperin 62). Queer permits agency, where the sexual subject draws from their cultural, sexual and experiential contexts to make and remake themselves. As Warner observes: 'Queers do a kind of practical social reflection just in finding ways of being queer' (Warner xiii). Queer is, then, a form of enabling practice of the sexual agent, whereby they have the 
tools by which to subvert traditional normativities with respect to sexuality, notably heteronormativity and hetero-patriarchal normativities.

Queer provides this opportunity because it is inherently deconstructive, and the elusiveness of saying what queer is arises from an afoundational and deconstructive impulse at its centre. Queer is almost metaphor for these practices put in motion by sexual agents, with an implicit transgressive assumption - that the sexual subject will seek to perform being queer against dominant normativities whilst creating their own subjective identities and practices of sexual desire and pleasure for themselves. As such queer involves rupturing assumptions and preconceptions of sexual identities, relations, orientations, behaviours and practices. What sex is, how it is enjoyed, with whom, in what discursive contexts, are all subject to malleability by the agent.

Two concepts, in particular, are central to this understanding of queer theory and its application to ageing sexuality: Judith Butler's performativity and Michel Foucault's notion of desexualisation. Butler maintains that gender is a cultural and regulatory fiction (Spargo, 1996). Sex and gender are both discursive constructions existing within a matrix of relations that legitimate and perpetuate heterosexuality because it is assumed that there is a causal relationship between "biological sex, culturally constituted gender and the "expression" or "effect" of both in the manifestation of sexual desire through practice" (Butler 1990, 23). For example, conventionally, a woman has been normatively constituted as female and feminine, which is expressed in heterosexual desire for her opposite, the heterosexual, masculine male. In order for women's gender to be intelligible, the expectation is that it conforms to the heterosexual matrix and that there is congruence between women's sex, gender and sexuality. ${ }^{47}$ For Butler, the laws that determine intelligibility are based on particular epistemological assumptions about the "knowability of the human" (Butler 2006, 183). Gender should not be understood as something we have but rather as signifying "a kind of doing" (Butler 2004, 1) or a performance. This recasting of gender and sexuality as performative constantly made and remade by the performance of difference and against the cultural conventions than encourage conformity within gendered and sexual dominant discourses - gives power and agency to the sexual subject. If they understand that their gender and sexuality has been constituted for them, internalised within them, normalised around them and imposed upon

${ }^{47}$ There is a substantive difference between how Butler and Nancy see intelligibility and the two should not be confused. 
them, they can also understand their performance can disrupt those conformities and allow them to reshape their sexual (and gendered) selves.

Foucault's notion of desexualization disrupts the assumed causality between sex, gender and sexuality, or more specifically, it challenges the normative relationship between sex organs, sexual practice and pleasure. He used the term 'desexualization of pleasure' in the context of sadomasochistic practices to refer to the separation of "sexual pleasure from genital specificity, from localization in or dependence on the genitals" (Halperin 89). Although he was writing specifically about SM practices, desexualisation can be applied more widely to encompass all sexual activity that decentres the sexual organs and/or eroticises other parts of the body.

When applied to the aging sexual body, queer would seem to be suggestive of a strategy to deconstruct pathologies and prejudices. Linn Sandberg (2008) has suggested that queer theory represents an underutilised tool for theorising old age and that concepts such as abjection and performativity can help us critically analyse and ultimately deconstruct what it means to 'do' ageing in intelligible ways.

Sandberg is sensitive to the distinction between the possibilities of queer disruptions of old age and positive recastings, particular in tune with neo-liberal consumerist discourses. For her, discourses of positive ageing are analogous with gay assimilationist strategies. Just as gay men and lesbians are tolerated in a heteronormative world as long as they do not represent too much of a threat to the 'ideal' of heterosexual coupledom, a position that has led to the increasing prevalence of what Lisa Duggan $(2002,2003)$ calls homonormativity, hence "being old does not have to be a negative thing as long as you live life like you used to live it" (Sandberg 124). Sandberg concludes:

Queer theory's turn to negativity and embracing shame can be seen as a way to deconstruct these ageist discourses and theorise old age differently. Regarding old age as performative in a similar way to gender moreover opens up a discussion of the role of failure in relation to age. Not being able to perform one's age has consequences also for one's gendered self, albeit differently for men and women. Sexuality plays a central role in this and queer theory's discussions on heteronormativity and hierachisations of sexualities could well be used also to 
discuss sexuality and old age. To include ageing and old age further in queer theory may in addition be a way of expanding and rethinking notions of normalcy and sexuality, where the discourse so pervasive on older people's sexuality; asexuality, needs a whole lot more attention. The discourses of positive ageing, how to become a successful retiree are based upon an understanding of ageing as a form of moral laxity, an inability to control and perform a desirable self, and moral discourse is on the whole very strong in relation to old age. These pregiven and naturalised moral codes of old age may be challenged through queer temporalities revealing the constructed nature of the life course framed by time of reproduction and time of inheritance. (134-135)

Sandberg may have some credence in seeing the potential of queer theory to subvert the pathology of aging sexuality, yet the intersubjective possibilities it holds out for - a recasting rather than deferral of pathologies and prejudices - is somewhat limited to the particular intersubjective circumstances of the performative act. Queer provides the means for exceptions and exceptional performances of the aging sexual self, but within the constructs and confines of an erotophobic heteronormative pathology of aging sexuality, which can be reinforced by class, disability and race (for example see McRuer 2006 and Kafer 2013). Queer performativity has often been itself queried as to how far it constitutes a politics of performance in its focus on discursive disruption within a material world where ideological power and material contexts subvert cultural politics (see Kirsch 2000, Floyd 2009). Butler has herself recognised this both in her working out of the balance of cultural and material forces $(1999,1993,1997)$ and more recently in political meditations exploring the performative in the context of dispossession (Butler and Athanasiou 2013). Here, the individuating and dispossessing discourses of neo-liberalism around property, ownership and consumption are contrasted with a self-dispossessing relationality that emphasises human interdependence and so contrasts a debilitating critique with a more promising (if limited) notion of how performativity can bring about materially constructive relations .

Such concerns raise the issue of how you perform this exceptionalism. In respect of an aging sexuality, the dominant approaches to older people's sex and sexuality detailed above are dissembling. Whilst relationality and interdependence of social subjects along axes of difference may be acknowledged, there is a specific sense in which queer encourages performativity in the 
context of particular closures that debilitate the capacity for performative politics. Indeed they constitute the oppositional constructs to be performed against, and represent potent and regressive formations.

Gilleard and Hicks (2011) provide an insightful reflection on this struggle in focusing on the notion of abjection in old age and the possibilities of its transgression. They outline the potency of abjection and the problems of engaging with abjection as a process that is continuous, making a distinction between the increasing frailty and lack of autonomy in the 'fourth age' as undermining those common strategies for attempting to retrieve dignity from abjection in the 'third age'. They offer two tentative possibilities for engaging with the persistence of abjection, which both transgress the naturalised and normalising discourses of aging and pathology and engage, in part, with Nancy's more enduring problem of intelligibility. They argue that a conjoined intimacy in caring has some possibility of providing an alternative to the slow debilitating impact of age as abjection, and they argue that the process of engaging with the 'other' of the aged sexual body is a potent reminder of the ontological vulnerability of the human condition.

Queer, then, provides a zone of engagement at which some tentative possibilities for transgression and reframing can arise to counter the power of abjection and debilitating discourses of the aged sexual body. Yet queer has its limitations in challenging the constitution of these pathologies beyond intersubjective change, with the possibility of cumulative transgressions shifting cultural discourses rather than providing exceptionalisms. Does a more qualified and pessimistic approach offer more?

Jacquelyn N. Zita (1998) provides a possible extension to framing strategies for transgression when she offers a speculation on the possibility of male lesbians in the context of the postmodernist body. Here, women centred men have a number of strategies by which to break the relationship between gender, sex and sexuality against the historicity of these conventional normative positionings of the body (85-108). If men identify as women-centred and seek to follow Stoltenberg (1989) in refusing to be a man and identify as lesbians, they have open to them the different strategies of: transsexual physical and psychological reconstruction of the body to the morphological criteria of 'female'; figuratively present themselves and valorise their experience as trans-gender and reject their somatic form; read themselves and insist on being read in a way that 
is genitally de-essentialising and so rejects somatic links to identity and being altogether; engage in 'genderfuck' and give priority to the meaning and performance of their sexuality as primary for themselves and for others in locating self (Zita 99). These might be seen as different performative strategies that enable the sexual agent to exercise their remaking of their sexual selves. Zita is ultimately pessimistic that this engagement of the transgressive self is sufficient to effect change, but does provide a framing that can rehearse the scope and limits to such possibilities.

If we begin to explore what strategies are open to older sexual agents, a number of possibilities suggest themselves that might mirror the framework Zita offers. Undoubtedly the 21st century is replete with technological and medicalised, procedural attempts to subvert the construction of aging and its debilitating impositions of aging sexual agents. Drugs like Viagra and Cialis allow for the elongation of sexual capacity. Surgical techniques can give the appearance of youth by changing the surface of the skin or through implants and augmentations. ICT offers a range of opportunities for presenting the self beyond age, whether in avatar form mediating the physical in the virtual, or through textual or mediated/visual representations and sexual interactions online. Technologies have advanced to the point where robotics and prosthetics mean that sophisticated replicates of human partners are becoming possible. Virtual reality programmes, computer generated augmentations such as pressure pads and visual aims that can be placed on the body, and the proliferation of the availability of diverse forms of pornography allow for self-contained sexual expression. In short, the 21 st century has enabled the technological extension of the sexual. These opportunities are largely ageless and can be afforded by anyone with access and disposable income - thereby raising the issue of class division - but these developments can clearly benefit the ageing sexual subject.

Of course, they do so primarily by changing the representation of the body to give it the appearance of being more youthful or adopting representational vestiges of youth - skin absent of blemishes, taut curves - or by negating the body of even its representational ideal altogether. Technology provides an opportunity to 'turn back the clock' as opposed to negate the clock altogether, or to render the clock a fiction in virtual time. Whilst somatic technologies provide alterations of the body, it is open to question as to whether the augmented corpus represents a confrontation or an exercise in deferral. As a discursive strategy, it offers the possibility of reclaiming hegemonic ground, but this is not the same as making bodies intelligible to the erotic 
gaze. Indeed, the maintenance of such a discursive strategy when written onto the body in technological or cosmetic forms is often one of acute medicalisation. Likewise, virtuality offers a completely different set of reference points to engaging the erotic, but they do not speak to corporeality unless it is to claim that it can be satisfactorily left behind, which sets an important agenda for exploration but addresses the 'problem' of the aging body by refusing it.

In a sense, this is a reprise of the discussion triggered by Sandberg (2008), but it does expand that discussion to recognise that whilst there are strong elements of regression to pathology present, or a limited intersubjective production of the exception to dominant discourses, this is one field of struggle that should not be wholly abandoned, and offers some possibilities for transgression if it is seen in its broader context. The extent to which it can be utilised more transgressively might depend on wider political agendas such as access, intersectional recognition and debates around post-human and augmented sexualities as different sexualities (see Weiss 1999 and Bradotti 2012, 2013).

Figurative strategies that reject somatic form might be seen as similarly partial in addressing the ageing body. They are explicitly engaged with putting distance between any explicit intelligibility of the corpus through discursive strategies that claim authorial authority in representation. Either, the reading of the ageing body is persuasively eroticised or the ageing body that is usually discursively represented as losing 'eroticism' is reconstructed with an erotic gaze. The fetishisation of sexual stereotypes such as 'cougars' - older women who are identified as sexual and indeed somewhat predatory of youthful partners - might be constituted as a rearticulation of the ageing body as erotic.

Of course, whilst it might provide an enabling discursive context for some women - a niche to occupy that allows the exercise of their sexuality - it might also be regarded as an exception that is subject to ridicule or stereotype, and this sort of discursive strategy trades off these positives and negatives. Here, the capacity to develop discursive strategies that are not easily incorporated into normalised and naturalised dominant discourses is important, and whilst it is another avenue cultural representation - of struggle - it should be again measured in relation to the constructs that dominate the cultural realm. Furthermore, the project of rejecting the somatic form for culturally constituted discursive readings is questionable and arguably a deferral rather than an engagement with the pathology of the aging sexual body. 
This discursive rejection of dominant somatic forms might be accompanied by a recasting not only of the body as erotic but the meaning of erotic itself. This corresponds to an approach that draws on Foucault's (1976) notion of desexualisation and Zita's (1998) genital de-essentialising. What is valuable about this extension of discursive strategy is that offers the possibility not simply of concentrating on how to retrieve or transgress for an eroticised aging sexual body, but to do so with a transformative eye to the contexts of age, sex and body that completely rejects any foundational points as to the necessary - particularly naturalised - aging of the corpus. It does not deny the corporeality of decay in the body, and the material context within which bodies move, but it does invite a strategy that links materiality and its discursive reading with wider struggles to retrieve sex from hetero-normativity, patriarchy, genito-centrism, reproductive biologism and medical performance models across the life course. In this sense it broadens and deepens the project of eroticising aging sexual bodies by inviting a rearticulation of contexts and constituents of the very conception of bodies, sexuality and eroticism and age.

This, in a sense, leads to the possibility Zita offers that it might be possible to 'engage in 'genderfuck' and give priority to the meaning and performance of their sexuality as primary for themselves and for others in locating self' (99). Zita is rightly wary of such a possibility. In a sense, it represents a perfect 'in the moment transgression' of self and sexual from all boundaries, where plasticity and fluidity can be repeatedly performed and autonomy celebrated. It could be said to be the highest expression of a queer intersubjectivity. Yet it crystalises the potential for queer to become closed from wider contexts within an intersubjective performance, potentially overstating the discursive against the material, and dissolving bodies into language - and thus failing to see the importance of Nancy's ontological caution.

Whilst queer does provide the basis for possible challenges to the hegemony of naturalisation and normalisation, seeing the terms of debate through the gaze of Nancy and Zita gives a sense that engaging with the sexual body, any corpus, is always an unending struggle of intelligibility, in which any sense of enabling comes through discursive struggles to dissemble and reconstruct first the focus of the ageing sexual body and then the very discursive and material constituents that frame that struggle. If this excursus on the ageing sexual body has any conclusion it is that this is a continuous struggle against a materiality that provides determinant points at strategies must be 
rethought and refreshed, not just against changing discursive pathologies but against that unintelligible yet signifying materiality of bodily change.

Whilst such a strategy might be daunting and imply at its most modest transgression in performance and at most a recasting of the sexual and the body in material contexts, it should not be seen as oppressively daunting. Sex is erotic play as much as a particular sensual performance. Brecher (2013) talks about the centrality of postponement and acting as a part of transgressive reaches for the erotic, and this particular political struggle can be pursued in part, in microcontexts, through theatre, dress, elaboration in performance, explorations with sensations, textures, pain and pleasure, smells and sounds. Small steps politically, but profoundly enjoyable and for all ages?

\section{Note}

The authors would like to thank the editors of InterAlia and two anonymous referees for comments that helped improve this article.

\section{Works Cited}

Braidotti, Rosi. Nomadic Theory: The Portable Rosi Braidotti. New York: Columbia University Press, 2012.

Braidotti, Rosi. The Posthuman, Cambridge: Polity, 2013.

Bouman, Walter, Jon Arcelus, and Sharon Benbow. "Nottingham Study of Sexuality \& Ageing (NoSSA I). Attitudes regarding sexuality and older people: a review of the literature." Sexual and Relationship Therapy 21.2 (2005): 149-161.

Brecher, Bob. "What is the Erotic?" Journal of the International Network for Sexual Ethics and Politics 1.1 (2013): 63-67.

Butler, Judith. Gender Trouble: Feminism and the Subversion of Identity London, Routledge. 1990.

---. Bodies that Matter: On the Discursive Limits of "Sex." London: Routledge, 1993.

---. "Doing Justice to Someone: Sex-Reassignment and Allegories of Transsexuality." The Transgender Studies Reader. Eds. Susan Stryker and Stephen Whittle. New York: Routledge, 2006.

---. Excitable Speech: A Politics of the Performative. London: Routledge, 1997.

---. Gender Trouble: Feminism and the Subversion of Identity $\left(10^{\text {th }}\right.$ Anniversary Edition). London: Routledge, 1999. 
---. Undoing Gender. Abingdon: Routledgem, 2004.

Butler, Judith, and Athenas Athanasiou. Dispossession: The Performative in the Political Cambridge: Polity, 2013.

Duggan, Lisa. "The New Homonormativity: The Sexual Politics of Neoliberalism." Materializing Democracy: Toward a Revitalized Cultural Politics. Eds. Russ Castronovo and Dana D. Nelson. Durham, NC: Duke University Press, 2002.

----. The Twilight of Equality? Neoliberalism, Cultural Politics, and the Attack on Democracy. Boston, MA: Beacon Press, 2003.

Floyd, Kevin. The Reification of Desire: Towards a Queer Marxism. Minneapolis: University of Minnesota Press, 2009.

Foucault, Michel. The History of Sexuality Vol. 1. An Introduction. Harmondsworth: Penguin, 1976.

---. The History of Sexuality Vol. 2. The Uses of Pleasure. Harmondsworth: Penguin. 1984a.

---. The History of Sexuality, Vol. 3. The Care of the Self. Harmondsworth: Penguin, 1984b.

Gilleard Chris, and Paul Higgs. "Ageing, Abjection and Embodiment in the Fourth Age." Journal of Aging Studies 25 (2011): 135-142.

Giddens, Anthony. Modernity and Self-identity: Self and Society in the Late Modern Age. Cambridge: Polity Press, 1991.

Gott, Merryn. "Sexual health and new ageing." Age and Ageing 35 (2006): 106-7.

Halperin, David, M. Saint Foucault: Towards a Gay Hagiography. New York: Oxford University Press, 1995.

Jagose, Anne-Marie. Queer Theory: An Introduction. New York: New York University Press. 1996.

Kafer, Alison. Feminist, Queer, Crip. Bloomington: Indiana University Press, 2013.

Kirsch, Max. Queer Theory and Social Change. London: Routledge, 2000.

Marshall, Barbara. L. and Stephen Katz. "Forever Functional: Sexual Fitness and the Ageing Male Body." Body \& Society 8.4 (2002): 43-70.

McRuer, Robert. Crip Theory: Cultural Signs of Queerness and Disability. New York: New York University Press, 2006.

Nancy, Jean-Luc. Corpus New York: Fordham University Press, 2008.

Plummer, Ken. Telling Sexual Stories: Power, Change and Social Worlds. London: Routledge, 1995.

---. "The Square of Intimate Citizenship: Some Preliminary Proposals." Citizenship Studies 5.3 (2001): 237-253.

---. Intimate Citizenship: Private Decisions and Public Dialogues. Seattle: University of Washington Press, 2003.

Oppenheimer, Catherine. "Sexuality in old age." Psychiatry in the Elderly. Eds. Robin Jacoby and Catherine Oppenheimer. Oxford: Oxford University Press, 2002.

Sandberg, Linn. "The Old, the Ugly and the Queer: Thinking old age in relation to queer theory." Graduate Journal of Social Studies 5.2 (2008): 117-139.

Stoltenberg, John. Refusing to be a Man: Essays on Sex and Justice. Portland: Breitenbush Books, 1989. 
Thompson, Neil. Anti-Discriminatory Practice ( $3^{\text {rd }}$ edition). Basingstoke: Palgrave, 2001.

---. Promoting equality: Challenging discrimination and oppression in the human services. MacMillan: Basingstoke, 1998.

Udis-Kessler, Amanda. "Challenging the Stereotypes." Bisexual Horizons Politics Histories Lives. Eds. Sharon Rose et al. London: Lawrence \& Wishart, 1996.

Vares, Tiina. "Reading the 'Sexy Oldie': Gender, Age(ing) and Embodiment." Sexualities 12.4 (2009): 503-524.

Warner, Michael, ed. Fear of a Queer Planet: Queer Politics and Social Theory. Minneapolis: University of Minnesota Press, 1993.

Wilton, Tamsin. "Genital Identities." Sexualising the Social: Power and the organisation of sexuality. Eds. Lisa Adkins and Vicki Merchant. Basingstoke: MacMillan, 1996.

Zita, Jacquelyn. N. Body Talk: Philosophical Reflections on Sex and Gender. New York: Columbia University Press, 1998. 